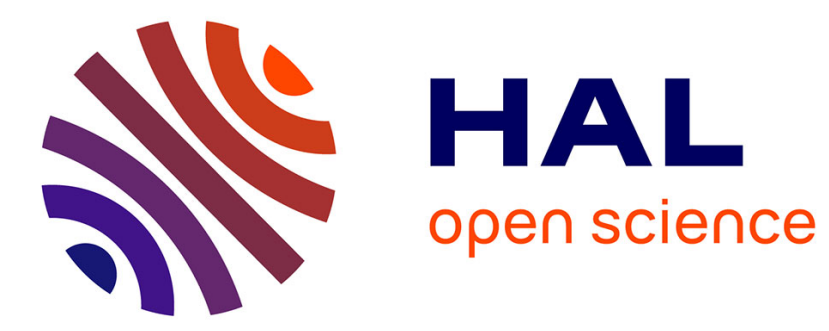

\title{
Friction and wear mechanisms of phenolic-based materials on High Speed Tribometer
}

Damien Méresse, Michel Watremez, Monica Siroux, Laurent Dubar, Souad Harmand

\section{- To cite this version:}

Damien Méresse, Michel Watremez, Monica Siroux, Laurent Dubar, Souad Harmand. Friction and wear mechanisms of phenolic-based materials on High Speed Tribometer. Journal of Tribology, 2013, 135 (3), 10.1115/1.4023803 . hal-02372575

\section{HAL Id: hal-02372575 \\ https: / uphf.hal.science/hal-02372575}

Submitted on 20 Nov 2019

HAL is a multi-disciplinary open access archive for the deposit and dissemination of scientific research documents, whether they are published or not. The documents may come from teaching and research institutions in France or abroad, or from public or private research centers.
L'archive ouverte pluridisciplinaire HAL, est destinée au dépôt et à la diffusion de documents scientifiques de niveau recherche, publiés ou non, émanant des établissements d'enseignement et de recherche français ou étrangers, des laboratoires publics ou privés. 


\title{
Friction and wear mechanisms of phenolic-based materials on High Speed Tribometer
}

\author{
Damien Meresse \\ Research Engineer \\ TEMPO Laboratory \\ University of Valenciennes \\ Valenciennes 59313, France \\ Email : damien.meresse@univ-valenciennes.fr \\ Monica Siroux \\ Assistant Professor \\ TEMPO Laboratory \\ University of Valenciennes \\ Valenciennes 59313, France
}

\author{
Michel Watremez \\ Assistant Professor \\ TEMPO Laboratory \\ University of Valenciennes \\ Valenciennes 59313, France
}

\author{
Laurent Dubar \\ Professor \\ TEMPO Laboratory \\ University of Valenciennes \\ Valenciennes 59313, France
}

\author{
Souad Harmand \\ Professor \\ TEMPO Laboratory \\ University of Valenciennes \\ Valenciennes 59313, France
}

\begin{abstract}
This work takes place in the understanding of the friction and wear mechanisms occurring in reinforced phenolic materials, widely used in organic braking pads. As the matrix is filled with a large variety of particles, the phenomena in the contact zone are complex and multi-physic. In a first approach the reinforcement is restricted to spherical steel particles with diameters in the range of the fibbers size. The influence of the sliding speed, the mean normal pressure and the contact temperature are examined and the benefits of using this kind of particle is as well discussed. The tribological tests are performed on a newly developed High Speed Tribometer designed to reproduce braking conditions. The results show that temperature is the most influential parameter, leading to a decrease of the friction coefficient. They further indicate that reinforcement pushes the loss of efficiency to a higher temperature. Optical observations and profilometer analysis show that the wear mechanisms are clearly dependent on friction conditions. These results improve our knowledge of wear debris formation and conditions leading to particle debonding in phenolic matrix material.
\end{abstract}

\section{Introduction}

In automotive braking systems, braking pads are made of composite materials containing at least ten different ingredients. More than 200 components are commonly used in commercial brake friction material. Due to the need to improve safety and comfort, a large number of new components have been added in recent years. They are classified by their ability to change the pads frictional behaviour. Reinforcement fibres are used to improve the mechanical properties, abrasive particles result in increased wear resistance and lubricant particles impart a stable friction coefficient. These components are surrounded in binder; in organic braking pads, this is typically a phenolic resin. The vehicle kinetic energy is mainly dissipated by heat generation at the disc-pad interface, which causes temperature elevation below $600^{\circ} \mathrm{C}$ as measured by Thevenet [1]. This heating leads to some surface degradations, such as oxidation, wear and thermo-mechanical failures by cracking [2]. The fade phenomenon resulting occurring with the degradation of the phenolic resin also results in a significant 
Some authors work on modified polymer formulations to avoid or to reduce fading at higher temperatures ( [3], [4]). Other works have focused on abrasive and lubricant component contents to produce a stable friction coefficient during braking application ( [5], [6]). Lu [7] has suggested the use of a combinatorial approach by classifying the additives according to their wear resistance. These approaches require a lot of experimental testing and do not always explain the benefit of each material. Although these tests allow the improvement of braking efficiency, there is some difficulty in explaining the thermomechanical mechanisms due to the number of different constituents and the synergy between them.

Eriksson [8] has underlined the fact that the contact surface of braking pads is governed by the formation and the deterioration of contact plateaus. Primary plateaus are composed of structural metal fibres formed by the deterioration of materials nearby with lower wear resistance. They form nucleation sites for the growth of secondary plateaus from wear debris compaction. The growth and destruction of contact patches are driven by the dynamics of wear in the brake system [9] and the circulation of wear debris [10]. These observations show that pad wear resistance is highly dependent on the link between the matrix and its reinforcements.

We initiate a study on tribological and wear mechanisms by focusing on the phenolic binder and one additive component in order to better understanding the contact zone. First, the phenolic resin material reinforcement is restricted to spherical steel particles $250 \mu \mathrm{m}$ in diameter. This is the main reinforcement component in organic brake pads. The friction and wear behaviour are investigated on a reduced scale tribometer for different sliding speeds and normal pressure, consistent with the conditions met in automotive braking conditions. Tests are performed on unreinforced and reinforced polymer samples to identify any benefit brought by the addition of steel particles. The influence of the temperature is determined using an inverse heat conduction model to get the temperature value at the pin contact surface.

\section{Experimental procedure}

The tribological behaviour of materials is studied using a High Speed Tribometer designed to reproduce the sliding speed and pressure occurring in automotive braking conditions. The device works in a pin on disc configuration and has been developed for the study of friction materials at a reduced scale. The pin and disc are dimensioned to keep the same energy repartition as the full scale, according to the rule determined by Roussette [11] from the Newcomb equation [12]. It is necessary to maintain the same ratio between the pin contact surface and the disc friction ring in both the real and experimental conditions.

\subsection{High speed tribometer device}

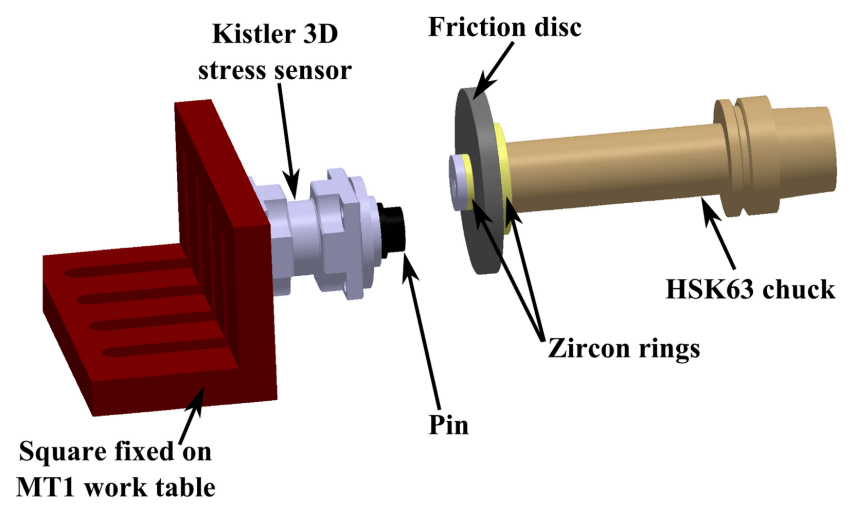

Fig. 1. High Speed Tribometer : pin on disc configuration

The High Speed Tribometer (Fig.1) has been developed by the TEMPO laboratory to reproduce severe thermomechanical conditions [13]. This device is constructed on a Siemens MT1 high-speed machining system. For the disc dimensions 
used in this study, it enables a sliding speed of $50 \mathrm{~m} . \mathrm{s}^{-1}$ at the mean sliding radius (15000rpm) for a nominal power of $41 \mathrm{~kW}$. The broach can endure up to $10 \mathrm{kN}$ of normal load and $5 \mathrm{kN}$ of tangential load.

The disc is fixed on an HSK63 chuck with zircon rings, which give thermal insulation from the machining system and allow the reproduction of symmetrical heat flow at half thickness. The broach can move on three translational axes and one rotational axis. The pin is rigidly fixed on a square placed on the machining work table. A 3D piezoelectric stress sensor (Kistler) between the pin and square allows the measurement of the normal and tangential loads on the pin during tribological tests. The sensor can work under loads of up to $20 \mathrm{kN}$ in the normal direction and $5 \mathrm{kN}$ in the tangential direction.

The temperature measurement is performed by a K-type thermocouple inserted $1 \mathrm{~mm}$ under the pin contact surface. This is fixed with a cement paste providing thermal properties close to those of the resin, so as to limit the heat flow perturbation induced by the hole. The sensor conductors are $0.1 \mathrm{~mm}$ in diameter, and the thermocouple weld is not insulated so as to allow a quick response $(<1 \mathrm{~ms})$.

\subsection{Sample preparation}

The friction material samples were manufactured in-house. Two compositions were tested at the pin side. One was a pure commercial phenolic resin, and the other was reinforced with $20 \%$ by volume of tempered steel particles. These were spherical particles that were industrially produced by blasting water on molten metal. To obtain a narrow size distribution, the components were sieved repeatedly. This procedure isolated particles from 200 to $300 \mu \mathrm{m}$ in diameter.

The resin powder and steel reinforcements were then mixed with a Turbula mixer, resulting in a homogeneous composition for components with different densities. The cylindrical pieces were obtained by heating the compositions for 15 min at $150^{\circ} \mathrm{C}$ and a typical pressure of $5 \mathrm{MPa}$. The compressed parts were initially $30 \mathrm{~mm}$ in diameter; they were reduced to $24 \mathrm{~mm}$ in diameter and $10 \mathrm{~mm}$ in thickness to follow the reduced scale rule.

The friction disc was made of low carbon steel (AISI 1015). The rotor was $100 \mathrm{~mm}$ in diameter with a thickness of $10 \mathrm{~mm}$. A mean friction radius of $36 \mathrm{~mm}$ allowed duplication of the heat flux repartition of the braking system of a European saloon car.

\subsection{Tested conditions}

In these experiments, tribological tests were performed at constant sliding speed. Initially, the broach is rotated at a set velocity. Then the rotor was moved in the normal direction, pressing the pin against the disc until the initial normal pressure was reached. This value was maintained by the stress sensor measurement. Finally, the disc and pin were locked in the normal position for the required duration.

The test duration was between $20 \mathrm{sec}$ and $3 \mathrm{~min}$, depending on the sliding speed and pressure conditions. Rotational speeds of 1325,2650 and 5300rpm were evaluated, corresponding to 5,10 and $20 \mathrm{~m} . \mathrm{s}^{-1}$ at the mean friction radius, respectively. These sliding speeds were met at the disc-pad interface for equivalent saloon car vehicle speeds of approximately 35,70 and $140 \mathrm{~km} \cdot \mathrm{h}^{-1}$. Various normal contact pressures were also investigated, ranging from $0.25-1.5 \mathrm{MPa}$. This corresponds to an automotive hydraulic pressure of 16 to 100bar in the brake calliper.

The High Speed Tribometer works in a rigid configuration. In some tests, significant normal load variations occur due to the rigidity of the system. The mean normal pressure is dependent of the competition between the material thermal expansion and surface wear. For most of the tests, the normal load is maintained around the mean normal pressure researched. The figure Fig. 2 represents the pressure, the friction coefficient and the contact temperature evolution for a test performed at $20 \mathrm{~m} . \mathrm{s}^{-1}$ and for a normal pressure of $1 \mathrm{MPa}$. The contact temperature is calculated by an inverse heat conduction method (described below) using the data from the thermocouple placed $1 \mathrm{~mm}$ under the pin surface.

\subsection{Running-in procedure}

To get contact on the entire pin surface, a running-in procedure was needed. As the High Speed Tribometer is constructed on a milling machine, it offers the ability to machine and mill once the disc and pin are fixed on. The running-in procedure was accomplished in two steps. First, the pin was fixed on the rigid square and milled on the device. This machining resulted in a pin surface perpendicular to the rotational axis. The milling operation employed a rotational speed of 1700rpm for a linear broach displacement of $240 \mathrm{~mm} \cdot \mathrm{min}^{-1}$. The disc was then mounted on the broach and machined with a work tool at the same rotational and linear displacement conditions.

As the HST works in a rigid configuration, there are no degrees of freedom. This procedure allowed us to start with the pin and disc surface parallel at the beginning of the tribological test. The disc friction ring profilometer analysis is shown in 


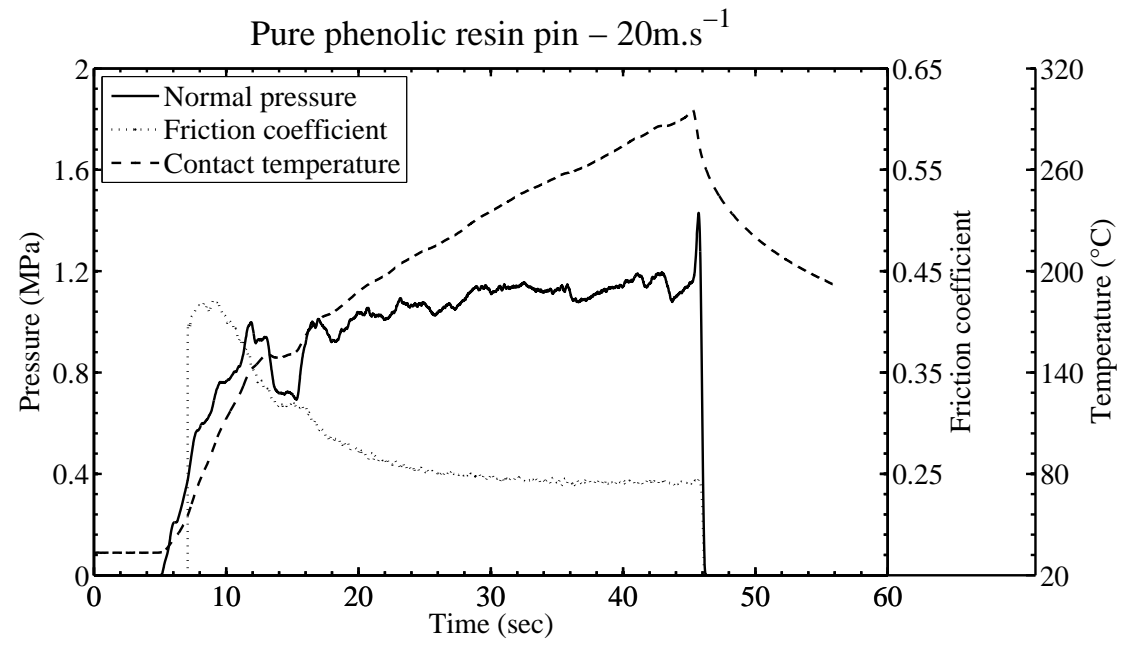

Fig. 2. Typical friction test results

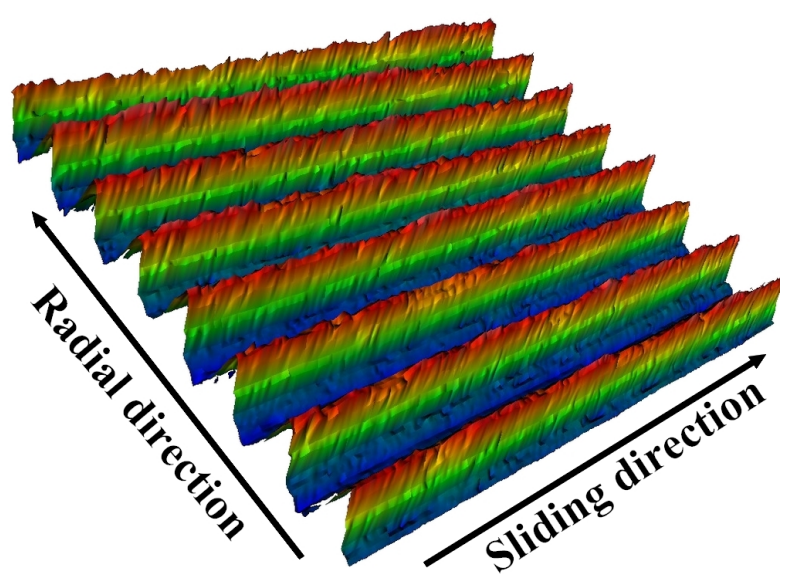

(a) Disc surface

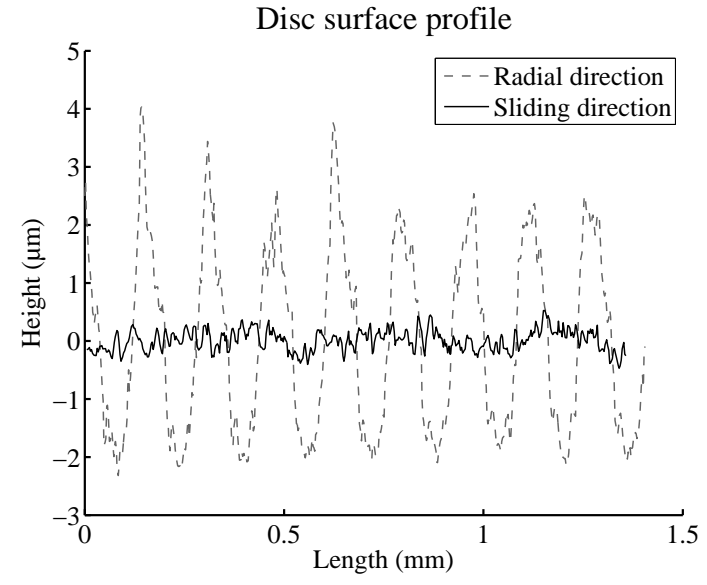

(b) Radial and sliding direction profiles

Fig. 3. Disc surface profile after machining procedure

figure Fig.3. Differences in roughness can be according to direction. In the sliding direction, the roughness $\left(\mathrm{R}_{A}\right)$ was lower than $0.15 \mu \mathrm{m}$, while it was close to $1.5 \mu \mathrm{m}$ in the radial direction. Machining the disc on the device in the same conditions allowed the use of the same disc surface profiles for all tribological tests.

The final running-in step was performed by rubbing the pin against the disc under the conditions to be tested (time, initial pressure, sliding speed). This was repeated at least ten times. The pin surface was checked after every tenth running-in test to verify that its entire surface was in contact with the rotor. If some areas were not worn, the running-in procedure was repeated until the circumferential lines printed by the disc appeared on the entire pin surface. This running-in allows getting worn surfaces with sliding distance in the range of 5000-8000m depending on the tested sliding speed. The worn surface can be considered similar at the beginning and at the end of a sliding test because the running-in is performed in the same friction conditions. This procedure allows reducing the sliding distance influence on the worn surfaces.

\subsection{Heat and temperature measurement}

The pin surface temperature is calculated by the inverse heat conduction method from the thermocouple temperature measurement. The function specification method, as given by Beck [14], allows the simultaneous identification of heat flux density and contact temperature evolution on the unknown boundary $z_{0}$. In this study, the pin is modelled in a $1 \mathrm{D}$ configuration along the thickness direction $\left(z_{e}\right)$. The heat conduction equation and thermal boundary conditions are given by (1), (2) and (3). 


$$
\begin{gathered}
\frac{\rho c_{p}}{k} \frac{\partial T}{\partial t}=\frac{\partial^{2} T}{\partial z^{2}} \\
-\left.k \frac{\partial T(z, t)}{\partial z}\right|_{z_{0}}=\frac{\partial^{2} T}{\partial z^{2}} \\
-\left.k \frac{\partial T(z, t)}{\partial z}\right|_{z_{e}}=\frac{\partial^{2} T}{\partial z^{2}}
\end{gathered}
$$

This technique is based on the sensitivity coefficient $\mathrm{X}$ providing the temperature variation at the sensor location for a unitary heat flux variation on the contact surface. The contact and heat flux variation can also be calculated by minimising the difference between the calculated and measured temperatures at the sensor location. The relevant algorithm is fully developed in [15].

It is necessary to evaluate the contact temperature by the inverse method because the poor thermal properties of the resin (Table 1) induce a thermal gradient between the contact surface and the sensor location. This iterative technique introduces some error in the heat flux estimation due to resolution on several future time increments. However, it is necessary to calculate boundary conditions when the sensitivity coefficients are poor due to material diffusivity or noisy data.

\begin{tabular}{lccc}
\cline { 2 - 4 } & $\begin{array}{c}\text { Thermal conductivity } k \\
\mathrm{~W} \cdot \mathrm{m}^{-1} \cdot \mathrm{K}^{-1}\end{array}$ & $\begin{array}{c}\text { Specific heat } c_{p} \\
\mathrm{~J} \cdot \mathrm{kg}^{-1} \cdot \mathrm{K}^{-1}\end{array}$ & $\begin{array}{c}\text { Density } \rho \\
\mathrm{kg} \cdot \mathrm{m}^{-3}\end{array}$ \\
\hline Resin & 0.5 & 1000 & 1450 \\
\hline Composite & 10.8 & 700 & 2730 \\
\hline
\end{tabular}

Table 1. Pin materials thermal properties in the range $\left(20-400^{\circ} \mathrm{C}\right)$

\section{Results}

The evolution of the friction coefficient and of the material wear are presented regarding four parameters. As well as temperature, sliding speed and mean pressure, matrix reinforcement can be considered to be a parameter for the friction condition. The influence of each parameter on the friction coefficient value is discussed. The raw data are extracted from tests and mean values are calculated according to the real measured pressure, the temperature and the sliding speed values. As the sliding speed remains constant, the friction coefficient value is compared regarding the three imposed conditions. The temperature domain is discretized from 40 to $350^{\circ} \mathrm{C}$ every $10^{\circ} \mathrm{C}$ and the pressure value is discretized on the range 0.25 $1.5 \mathrm{MPa}$ every $0.125 \mathrm{MPa}$. Although a mean normal pressure is chosen at the beginning of the test, normal load variations occur due to the tribometer configuration. Therefore this parameter can be observed on the range $0.25-1.5 \mathrm{MPa}$. The real load measurement is used to get the friction coefficient dependence instead of the initial normal pressure. To interpret the parameter influences on the friction coefficient value, we have selected the test results where the standard deviation of the researched mean normal pressure is lower than $25 \%$.

\subsection{Friction behaviour}

\subsubsection{Mean normal pressure and sliding speed effects}

In figure Fig.4, the evolution of the friction coefficient is plotted against sliding speed at the mean radius on the disc. For different pressure, temperature and material composition, the trend of decreasing friction coefficient can be observed as sliding speed increases. For a pin surface temperature closed to $50^{\circ} \mathrm{C}$ (Fig. 4(a)), the mean pressure exhibits an influence on the friction coefficient, while reinforcement seems to have only a slight impact on it. However, the difference between the 


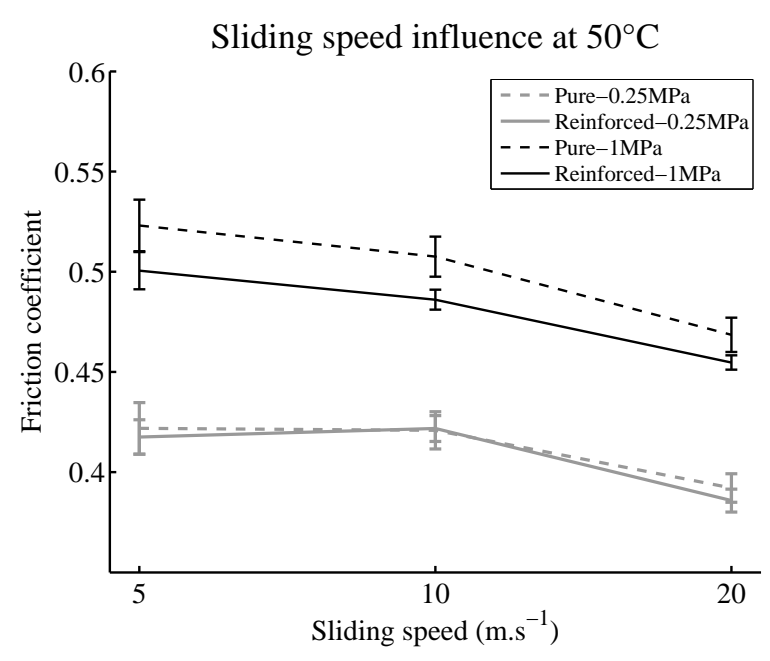

(a) $50^{\circ} \mathrm{C}$

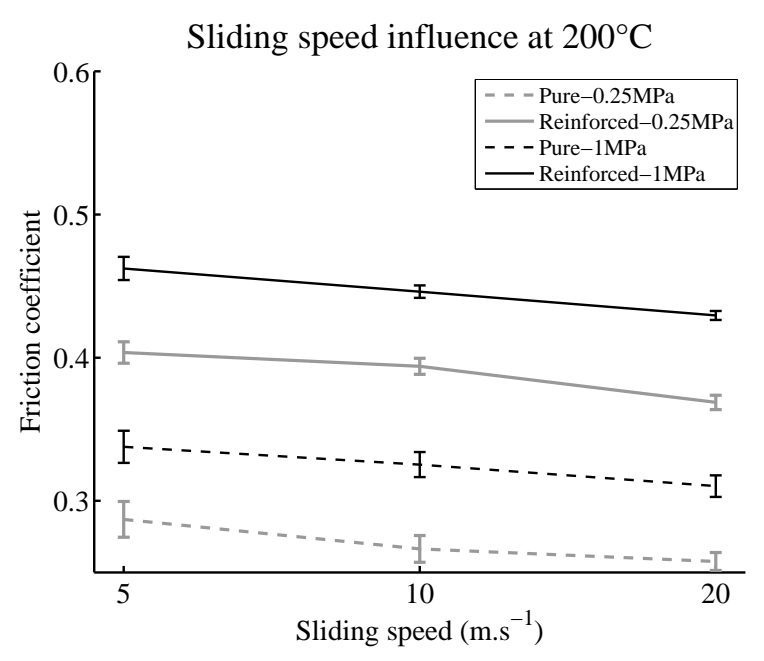

(b) $200^{\circ} \mathrm{C}$

Fig. 4. Sliding speed influence on friction coefficient

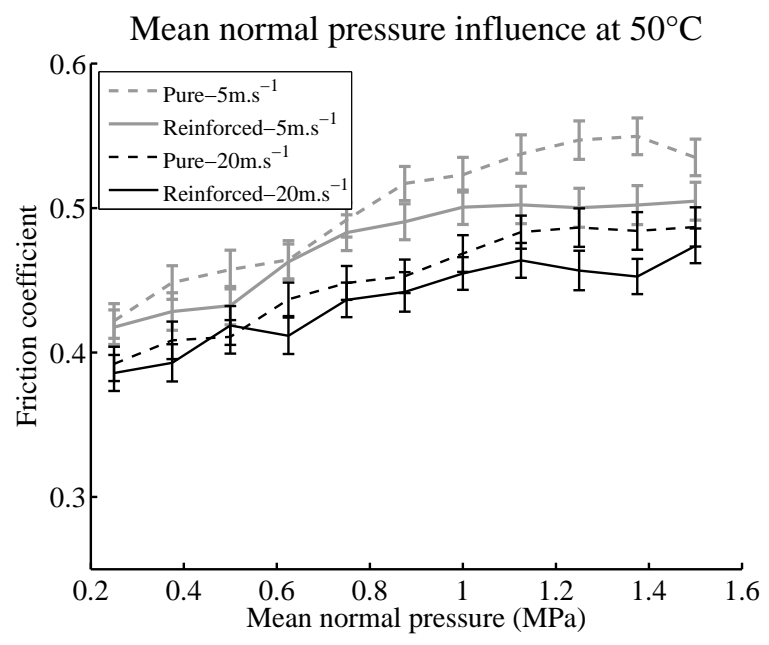

(a) $50^{\circ} \mathrm{C}$

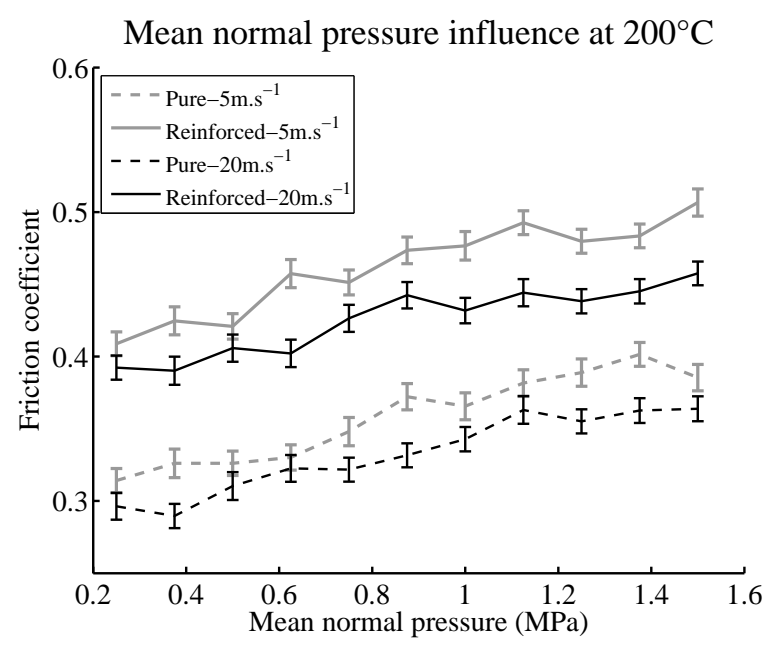

(b) $200^{\circ} \mathrm{C}$

Fig. 5. Mean normal pressure influence on friction coefficient

friction coefficient values for the pure matrix and the resin reinforced with steel particles increases for temperatures up to $200^{\circ} \mathrm{C}$ (Fig. 4(b)). In all cases, the friction coefficient value grows with decreasing sliding speed. This behaviour is widely observed in braking material (anti-fade) [16].

The friction coefficient values indicating the influence of mean normal pressure are presented in figure Fig. 5 for constant temperature. In all cases, the coefficient of friction grows with normal load. If we observe the low temperature condition (Fig.5(a)) for reinforced and unreinforced materials, the average coefficient increases $(+0.1)$ with pressure, growing from $0.25-1.5 \mathrm{MPa}$. At $200^{\circ} \mathrm{C}$ (Fig.5(b)), this increase is less important, but the material composition dependence can be observed. The friction coefficient values are in the range of 0.3-0.35 for an unreinforced pin, and larger for the reinforced matrix. The increase of friction coefficient with pressure has been reported by Jang [6] in work on the effects of metal fibres on automotive brake materials. This phenomenon is generally explained by the deformation of surface asperities, resulting in the growth of real contact area [17] and leading to higher friction coefficient values.

\subsubsection{Surface temperature effect}

The temperature dependence of the friction coefficient can clearly be observed in figure Fig.6. Regardless of the pressure, sliding speed and reinforcement, the friction coefficient value generally decreases when the temperature increases. In all cases, the temperature-dependent friction behaviour can be decomposed into three stages. In the first stage, the friction coefficient is only slightly affected by temperature elevation. Then the coefficient rapidly decreases once critical temperature 
Temperature influence at $0.5 \mathrm{MPa}$

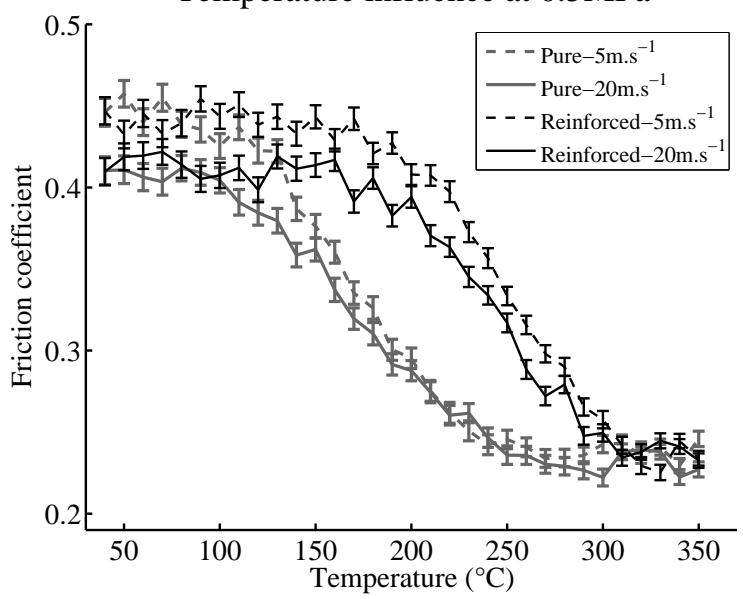

(a) $0.5 \mathrm{MPa}$
Temperature influence at $1.5 \mathrm{MPa}$

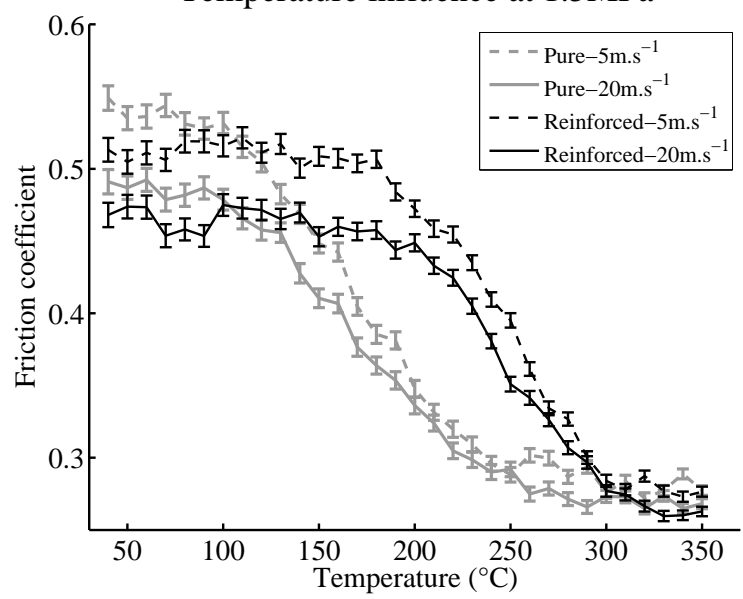

(b) $1.5 \mathrm{MPa}$

Fig. 6. Temperature influence on friction coefficient

Resin mechanical properties vs. temperature

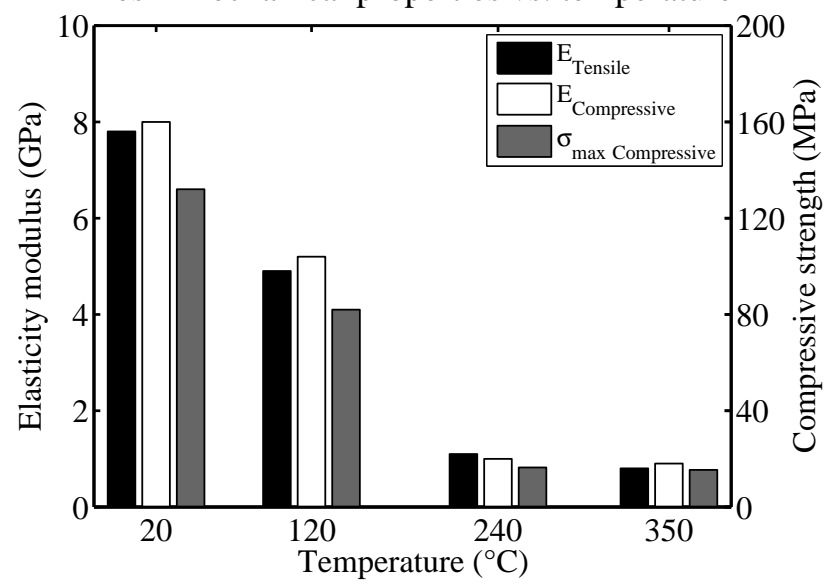

Fig. 7. Resin elastic modulus as a function of temperature

value $\left(\mathrm{T}_{C}\right)$ is reached. This obviously depends most strongly on material composition. The critical value $\mathrm{T}_{C}$ is close to $120^{\circ} \mathrm{C}$ for an unreinforced matrix and close to $200^{\circ} \mathrm{C}$ in the case of steel reinforced resin for both contact pressures. In the final stage, the friction coefficient becomes approximately constant above $300^{\circ} \mathrm{C}$. Friction loss with temperature elevation can be compared with the fading effect observed in braking conditions. For our tests, the fading phenomenon appeared for lower temperatures, compared to its appearance at $300^{\circ} \mathrm{C}$ in the experimental tests conducted by for Gurunath et al. [18]. However, the authors work with materials containing a large number of abrasives and lubricant constituents and particles may have led to noticeably different behaviour.

Rheological tests have been performed on pure phenolic material to explain the friction loss with temperature elevation. The tensile and compressive behaviours have been investigated for different temperatures conditions. Mechanical tests were conducted on an INSTRON dynamometer in a room chamber adapted as a tensile machine. Strain was monitored using the Digital Imaging Correlation technique for capture of the specimen. Tests were performed in the quasi-static strain rate condition with a constant velocity of $3 \mathrm{~mm} \cdot \mathrm{s}^{-1}$. The temperature influence on the elastic modulus of the phenolic resin is plotted in Fig. 7 for 20, 120, 240 and $350{ }^{\circ} \mathrm{C}$.

We can observe that the resin stiffness and strength are strongly dependent on the studied temperature range. From $120^{\circ} \mathrm{C}$, the stiffness value from the compressive test is approximately $5.1 \mathrm{GPa}$ compared to $8 \mathrm{GPa}$ at $20^{\circ} \mathrm{C}$. At $240^{\circ} \mathrm{C}$, the stiffness decreases to $1.1 \mathrm{GPa}$, and no significant variation appears upon increase to the highest temperature $(0.95 \mathrm{GPa}$ at $350^{\circ} \mathrm{C}$ ). A similar trend can be observed for the resin compressive strength. It decreases from 132MPa at ambient room to $16 \mathrm{MPa}$ at $350^{\circ} \mathrm{C}$. The material is also more ductile at high temperature; the longitudinal failure strain is approximately 
$8 \%$, compared to its value of less than $0.5 \%$ at ambient temperature. The link between the degradation of the resin and the friction loss is generally observed [18]. By comparing the friction coefficient evolution and the mechanical properties of the resin with the temperature, can be noticed. The comparison with reinforced pins shows the benefit and the delay in friction brought by the steel particles.

\subsubsection{Reinforcement benefits}

From the tribological test results (Figs. 4-6), some differences can be observed resulting from matrix reinforcement. The most significant effect is that the onset of high-temperature friction loss is delayed from approximately 120 to $200^{\circ} \mathrm{C}$. This benefit can be explained by a weakly temperature-dependent friction coefficient of the metal particles employed in these tests. For temperatures below $350^{\circ} \mathrm{C}$, there is no significant change in the rheological properties of steel [19], and steel-steel adhesion may not occur in this temperature range.

Particle addition seems to have a smaller effect on the normal pressure and sliding speed dependence of the friction properties. In figure Fig.4, a decrease of the friction coefficient is observed for pure phenolic resin and reinforced material. Considering the influence of normal pressure (Figure 5(a)), the low-temperature friction coefficient value is higher for unreinforced material. Significant differences can be observed at $200^{\circ} \mathrm{C}$ due to strong coupling between the thermal effect and the material composition. Between 300 and $350^{\circ} \mathrm{C}$, the friction behaviour seems to be similar for unreinforced and reinforced material sliding at the same pressure.

\subsection{Wear behaviour}

The worn surfaces were analysed with optical and SEM observations and with profilometer measurements. These measurements were performed with a Zygo NewView 7300. This device allows height measurements with spatial resolution of $0.1 \mathrm{~nm}$ and in-plane resolution of $0.5 \mu \mathrm{m}$. Optical observations enable the examination of wear debris formed during the tests. SEM observations highlight that the severe friction conditions favour the particle debonding behavior. Wear analysis of temperature and reinforcement effects will improve the understanding of the evolution of the friction coefficient.

\subsubsection{Temperature effect on matrix}

As previously stated, temperature seems to be the most influential parameter on friction behaviour. At the maximum temperature reached during the test, significant differences are observed on the worn surfaces of the pin and disc. For low temperature elevation (Fig.8(a)), below $50^{\circ} \mathrm{C}$, the pin roughness $\mathrm{R}_{A}$ is approximately $0.6 \mu \mathrm{m}$ in the radial direction and $0.1 \mu \mathrm{m}$ in the sliding direction. The radial roughness periodicity is consistent with the value measured on the disc side. For low pin surface heating, the resin seems to be ploughed by the disc, and the wear is dominated by abrasive phenomena. A small amount of resin material is transferred to the disc friction ring (Fig.8(b)).

For the most severe braking conditions producing temperature elevation above $300^{\circ} \mathrm{C}$, the pin surface displays more irregularities, as shown in Fig.8(c). Although these tests are performed with unreinforced material, some preferential contact plateaus can be observed, and cavities attest to significant material loss. This may indicate contact localisation on patches of the surface. The wear mechanism seems to be dominated by plate delamination. A significant material layer can also be observed at the disc side for tests with temperature elevation below $300^{\circ} \mathrm{C}$ (Fig.8(d)). This may correspond to the detachment of resin plate from the pin side, and adhesive phenomena are probably activated by surfaces heating.

\subsubsection{Benefits of reinforcement}

Steel particles can easily be observed on the pin surface profiles (Fig.9). For our simplified composite material, the reinforcements form preferential contact patches, as described by Eriksson [8] for organic braking pads. For low temperature conditions (Fig. 9(a)), contact plateaus are generally in the range of 100-250 $\mu \mathrm{m}$ in diameter and $4-7 \mu \mathrm{m}$ in height. Patches can locally have larger sizes when some particles are aggregated.

In the case of high temperature elevation, some differences appear on the worn surfaces. The figure Fig.9(b) shows the surface profile for a test with temperature elevation up to $350^{\circ} \mathrm{C}$. Preferential contact patches are observed as well, but their height seems to be dependent on temperature. Plateau diameters are in the range of $80-300 \mu \mathrm{m}$. Their development is due to the abrasive wear of the steel particles against the disc. Regarding plateau height, the mean distance between the matrix and the steel surface is more important at higher temperature. Values from 8 to $15 \mu \mathrm{m}$ were measured, and the height increased with maximum temperature elevation reached at the pin surface. This phenomenon can be explained by a decrease in matrix wear resistance at elevated temperature and by the typically high thermal expansion of polymer materials [20]. The resin 


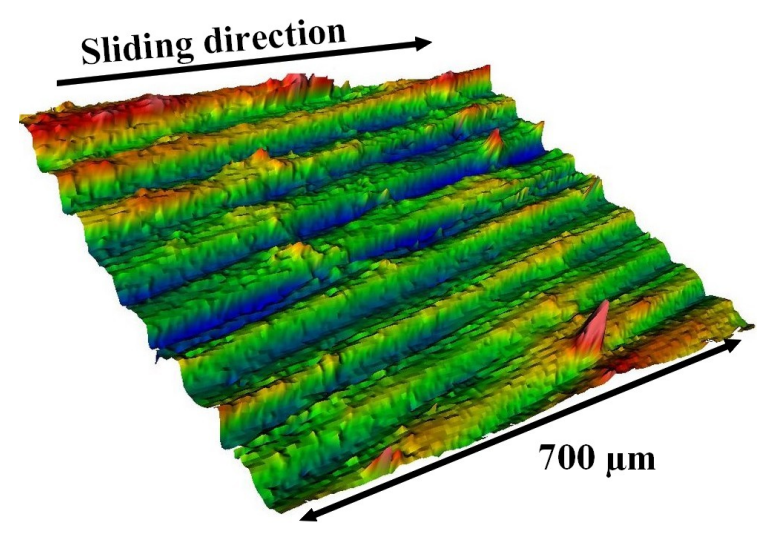

(a) Pin surface profile : $50^{\circ} \mathrm{C}$

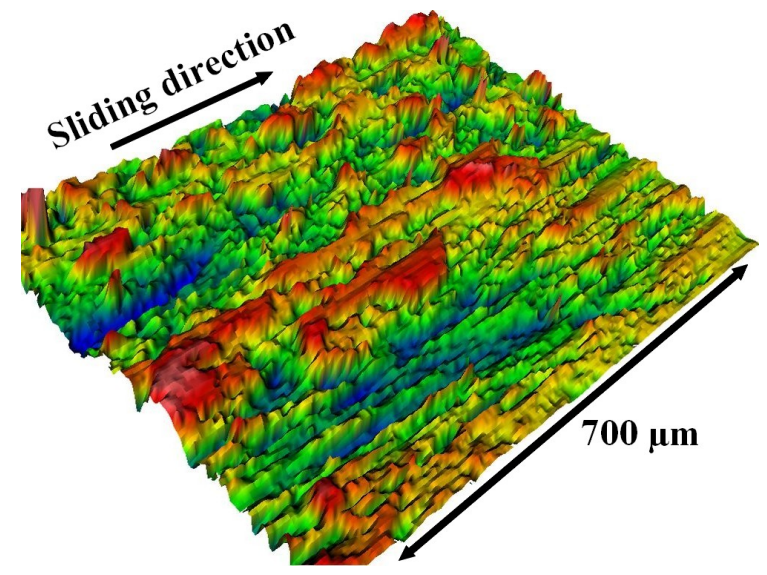

(c) Pin surface profile : $300^{\circ} \mathrm{C}$

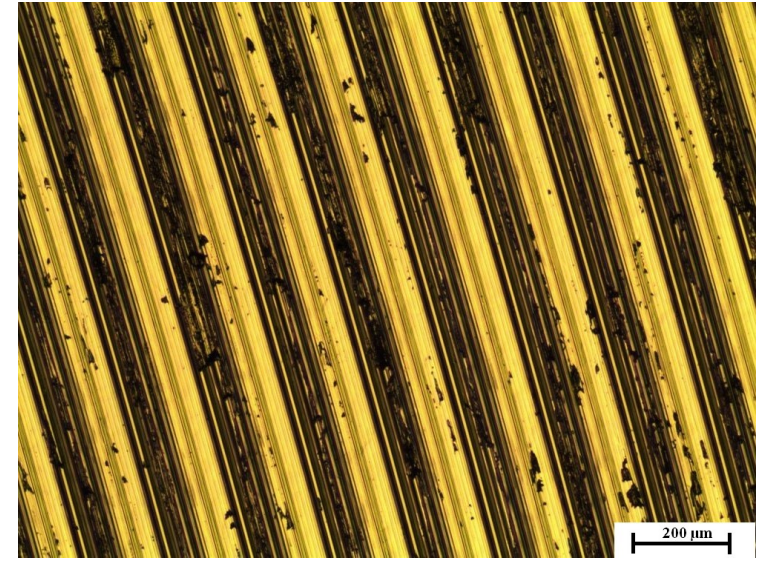

(b) Disc optical observation : $50^{\circ} \mathrm{C}$

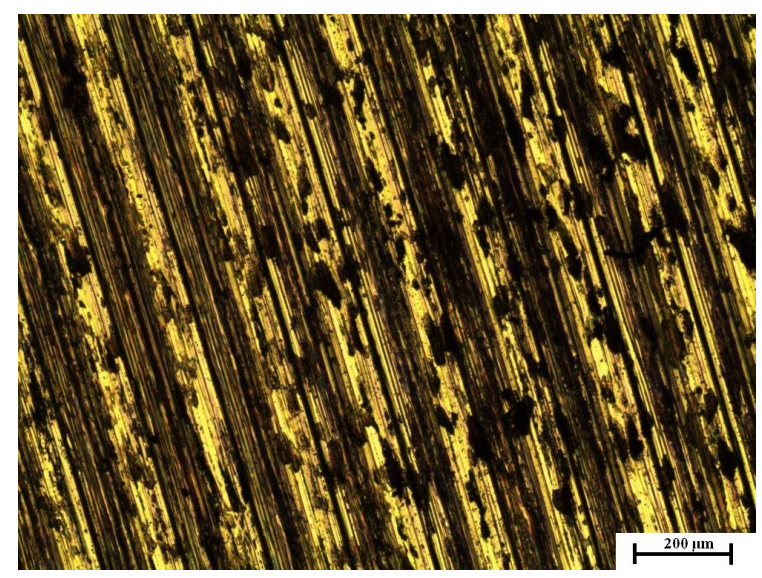

(d) Disc optical observation : $300^{\circ} \mathrm{C}$

Fig. 8. Pure phenolic pin surfaces obtained using profilometer analysis

must expand during the test, be worn and pull back when cooling.

Another observed surface temperature-dependent quantity is the particle debonding ratio. The highest rate of debonding particles occurred for tests under high pressure and temperature, up to $350^{\circ} \mathrm{C}$. Spherical cavities measured with the optical profilometer (Fig.9(c)) show that particles have been pulled out by the disc. In the case of low temperature elevation, the number of cavities was negligible compared with the high temperature case.

Rheological tests have been performed on the reinforced polymer to evaluate the required energy to debond the steel particle from the resin matrix [21]. A description of the mesoscopic particle/resin interfaces is obtained from a notch-bend specimen. The parameters of this description are calculated from the macroscopic results using analytic formulations provided by Tan [22]. This allows the identification of energy released by fracture propagation in the matrix and by fracture propagation at the interface. Tests have been performed at ambient temperature and at $350^{\circ} \mathrm{C}$. The results show that the required energy to debond a particle reduced by a factor of three in higher temperature conditions $\left(20^{\circ} \mathrm{C}: 72 \mathrm{~J} \cdot \mathrm{m}^{-2}, 350^{\circ} \mathrm{C}\right.$ : $24.8 \mathrm{~J} . \mathrm{m}^{-2}$ ). Although tests are performed in quasi-static conditions, this may explain the higher debonding rate above $300^{\circ} \mathrm{C}$ in tribological tests.

The figure Fig.10 shows particles rubbed in different friction conditions. On Fig.10(a), the pin has been submitted to low pressure and sliding speed leading to low temperature elevation $<50^{\circ} \mathrm{C}$. The wear of the particle seems to have a breakable behaviour. This could be explained by the fact that particles are obtained by a quench hardening process. Steel particles may remain in a martensitic phase. On Fig.10(b), the surface has an high temperature elevation due to severe pressure and sliding speed conditions imposed. The wear pattern of the particle seems to be less breakable. The particle surface seems to be rubbed in an abrasive wear mode. On the two side, wear debris can be observed. The major difference in the resin is the amount of cracks. In the low friction conditions (Fig.10(a)), only some cracks are observed. For the severe conditions (Fig.10(b)), more cracks appears on the resin surfaces. These cracks are also visible along the particle-matrix interface, majority on the top and left sides on this picture. These observations are in the same way that the conclusions on 


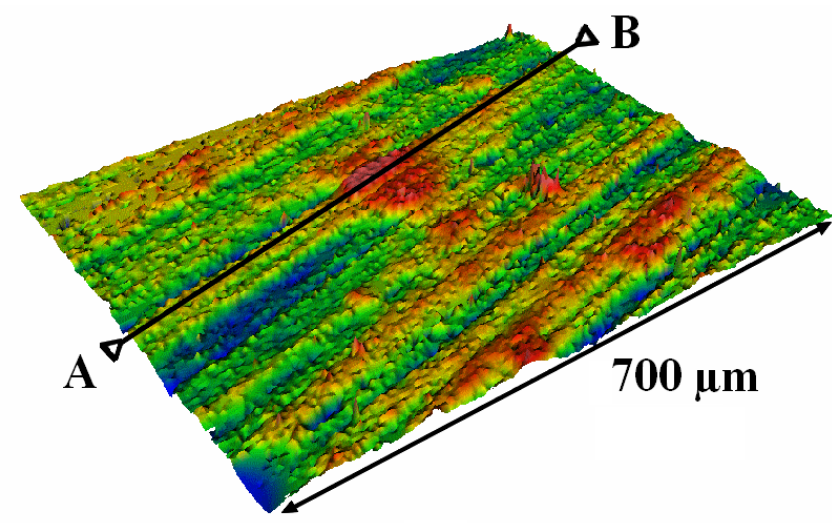

(a) $50^{\circ} \mathrm{C}$

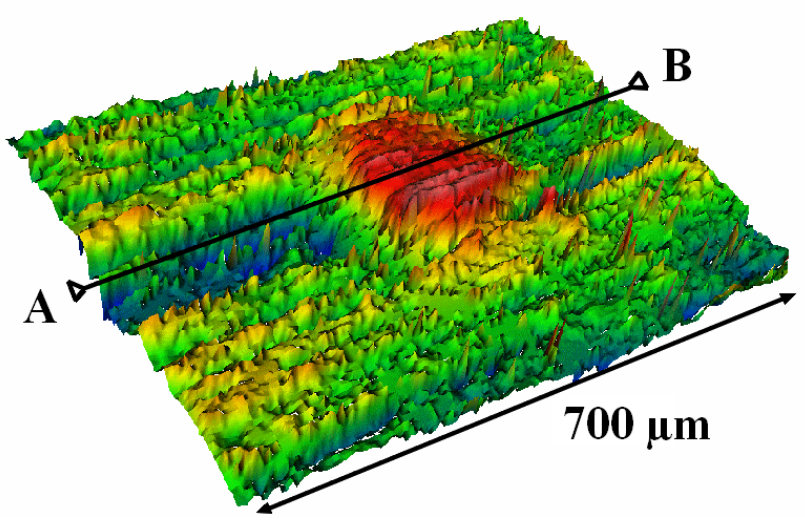

(c) $350^{\circ} \mathrm{C}$ (with debonding)

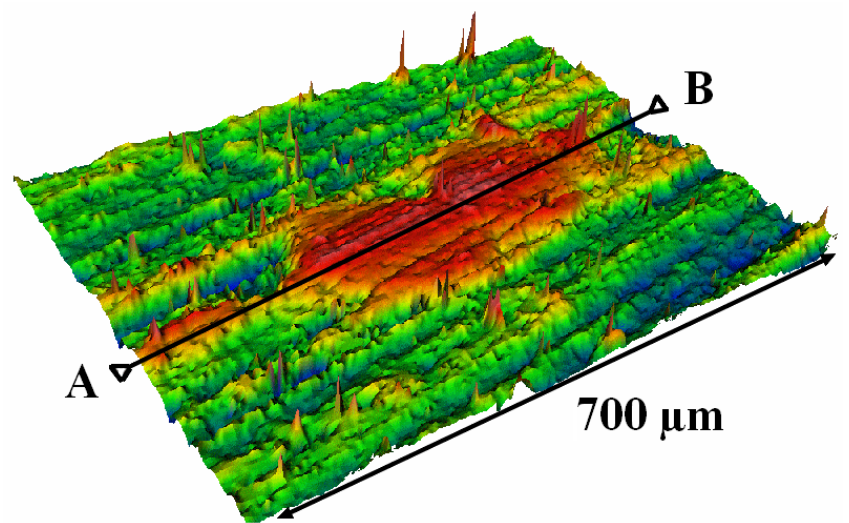

(b) $350^{\circ} \mathrm{C}$
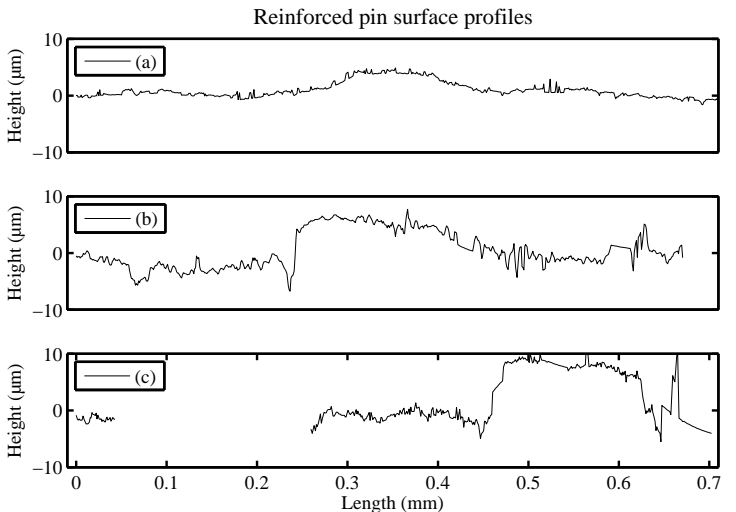

(d) Surfaces profiles along $\mathrm{AB}$

Fig. 9. Reinforced pin surfaces obtained using profilometer analysis

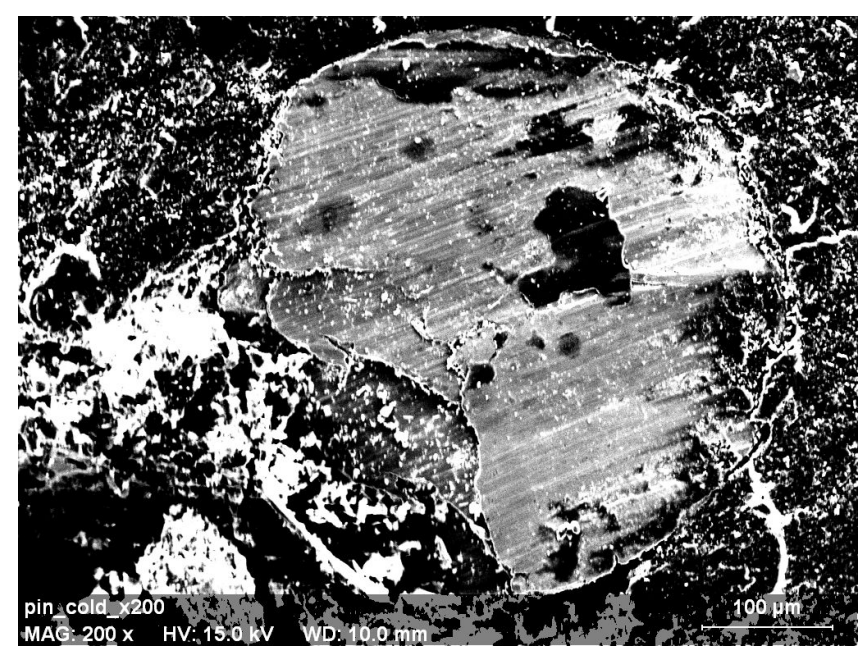

(a) Low temperature elevation $\left(<50^{\circ} \mathrm{C}, 5 \mathrm{~m} \cdot \mathrm{s}^{-1}, 0.25 \mathrm{MPa}\right)$

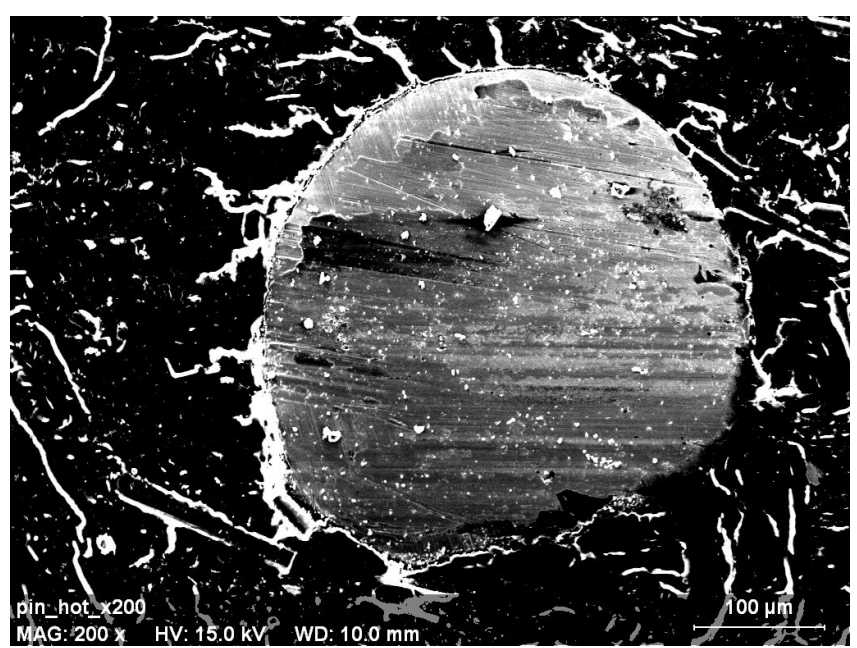

(b) High temperature elevation $\left(>300^{\circ} \mathrm{C}, 20 \mathrm{~m} \cdot \mathrm{s}^{-1}, 1 \mathrm{MPa}\right)$

Fig. 10. SEM observations of steel particles

the profilometer analyses.

\section{Conclusions}

Most studies on braking materials examine the friction and wear properties of complex compositions. This makes phenomena hard to understand due to numerous parameters and synergy among each other. In this work, we examined a simple phenolic material with reinforcements limited to steel particles. Tribological tests were performed on a High Speed Tribome- 
ter, allowing the reproduction of braking tests at a reduced scale.

One interesting result discovered in the present study is the dependence of friction behaviour on surface temperature condition and the corresponding benefit of reinforcement. For both the pure phenolic pin and the composite material, the friction coefficient was significantly affected by the temperature value. This phenomenon is correlated by the temperature-dependent rheological behaviour of the polymer. The addition of steel particles results in an increase of the critical temperature $\mathrm{T}_{C}$ leading to friction loss from $120^{\circ} \mathrm{C}$ to $200^{\circ} \mathrm{C}$.

The temperature and reinforcement influences can also be observed on the wear behaviour. For the pure phenolic resin pin, the temperature parameter determines the dominant mode of wear. Abrasive wear at low temperature is replaced by polymer plate delamination at elevated temperature. This can be observed on the disc surface by significant material transfer. Steel particles form preferential contact patches, as described in braking literature. However, some differences can be observed in the maximum temperature elevation. First, plateau height grows in the case of high temperature elevation. Second, reinforcement debonding seems to be easier up to $350^{\circ} \mathrm{C}$. The crack formation has been highlighted around the particlematrix by SEM observations.

\section{Achnowledgements}

The present research work has been supported by the International Campus on Safety and Intermodality in Transportation, the Nord-Pas-de-Calais Region, the European Community, the Regional Delegation for Research and Technology, the Ministry of Higher Education and Research and the Carnot Institute. The authors gratefully acknowledge the support of these institutions.

\section{References}

[1] Thevenet, J., Siroux, M., and Desmet, B., 2010. "Measurements of brake disc surface temperature and emissivity by two-color pyrometry". Applied Thermal Engineering, 30(6-7), May, pp. 753-759.

[2] Cristol-bulthe, A., Desplanques, Y., Degallaix, G., and Berthier, Y., 2008. "Mechanical and chemical investigation of the temperature influence on the tribological mechanisms occurring in OMC/cast iron friction contact". Wear, 264(910), Apr., p. 815-825.

[3] Mutlu, I., Eldogan, O., and Findik, F., 2006. "Tribological properties of some phenolic composites suggested for automotive brakes". Tribology International, 39(4), p. 317-325.

[4] Bijwe, J., Nidhi, Majumdar, N., and Satapathy, B., 2005. "Influence of modified phenolic resins on the fade and recovery behavior of friction materials". Wear, 259(7-12), Aug., pp. 1068-1078.

[5] Cho, M., Ju, J., Kim, S., and Jang, H., 2006. "Tribological properties of solid lubricants (graphite, Sb2S3, MoS2) for automotive brake friction materials". Wear, 260(7-8), p. 855-860.

[6] Jang, H., Ko, K., Kim, S., Basch, R., and Fash, J., 2004. "The effect of metal fibers on the friction performance of automotive brake friction materials". Wear, 256(3-4), p. 406-414.

[7] Lu, Y., 2006. "A combinatorial approach for automotive friction materials: Effects of ingredients on friction performance”. Composites Science and Technology, 66(3-4), p. 591-598.

[8] Eriksson, M., and Jacobson, S., 2000. “Tribological surfaces of organic brake pads". Tribology International, 33(12), Dec., pp. 817-827.

[9] Ostermeyer, G., 2003. "On the dynamics of the friction coefficient". Wear, 254(9), p. 852-858.

[10] Berthier, Y., Vincent, L., and Godet, M., 1988. "Velocity accommodation in fretting”. Wear, 125(1-2), p. 25-38.

[11] Roussette, O., Desplanques, Y., and Degallaix, G., 2003. "Thermal representativity of tribological reduced-scale testing". Comptes Rendus Mecanique, 331(5), p. 343-349.

[12] Newcomb, T. P., 1959. "Transient temperatures attained in disk brakes". British Journal of Applied Physics, 10(7), July, p. 339-340.

[13] Meresse, D., Harmand, S., Siroux, M., Watremez, M., and Dubar, L., 2012. "Experimental disc heat flux identification on a reduced scale braking system using the inverse heat conduction method". Applied Thermal Engineering, 48(0), Dec., pp. 202-210.

[14] Beck, J., and Blackwell, B., 1985. Inverse heat conduction : ill-posed problems. Wiley, New York.

[15] Meresse, D., Siroux, M., Watremez, M., Dubar, L., and Harmand, S., 2010. "Thermal study of pin on disc sliding contact in automotive braking conditions". In JEF2010, 6th European Conference on Braking.

[16] Symmons, G., and Mcnulty, G., 1986. “Acoustic output from stick-slip friction”. Wear, 113(1), Dec., pp. 79-82.

[17] Persson, B., 2000. "Sliding friction : Physical principles and applications". Spinger-Verlag ed. Berlin, p. 45-91. 
[18] Gurunath, P., and Bijwe, J., 2007. "Friction and wear studies on brake-pad materials based on newly developed resin". Wear, 263(7-12), p. 1212-1219.

[19] Boyer, H., and Gall, T., 1985. Metals Handbook, american society for metals ed.

[20] Shengzu, W., Sabit, A., and Bor, Z., 1997. "Mechanical and thermo-mechanical failure mechanism analysis of fiber/filler reinforced phenolic matrix composites". Composites Part B: Engineering, 28(3), p. 215-231.

[21] Meresse, D., Siroux, M., Watremez, M., Harmand, S., and Dubar, L., 2011. "Estimation of three-dimensional distribution of heat flux on the pin frictional surface during a pin on disc test". AIP Conference Proceedings, 1353(1), May, pp. 1137-1142.

[22] Tan, H., Liu, C., Huang, Y., and Geubelle, P., 2005. "The cohesive law for the particle/matrix interfaces in high explosives". Journal of the Mechanics and Physics of Solids, 53(8), p. 1892-1917. 